\title{
LIVROS DIDÁTICOS EM MATO GROSSO (DO SUL) NO SÉCULO XX: UM CATÁLOGO ANALÍTICO
}

\author{
Textbooks in Mato Grosso (South) in the Twentieth Century: an Analytical Catalog \\ Manuales Escolares en Mato Grosso (Del Sur) en el Siglo XX: um Catalogo Analitico
}

Kênia Hilda Moreira*

\begin{abstract}
Resumo
Objetiva-se apresentar os procedimentos metodológicos para a criação de um catálogo analítico de livros didáticos que circularam em Mato Grosso (do Sul) no século XX, bem como a análise dos resultados dessa busca que localizou 266 livros didáticos. A análise considera o período de publicação das obras, a recorrência das disciplinas, autores e obras, a presença de livros regionais e as editoras.
\end{abstract}

PALAVRAS-CHAVE: História da Educação. Livros Didáticos. Sul de Mato Grosso.

\begin{abstract}
The objective is to present the methodological procedures for the creation of an analytical catalog of textbooks that circulated in Mato Grosso (South) in the twentieth century, as well as the analysis of the results of this search that located 266 textbooks. The analysis considers the period of publication of the works, the recurrence of the disciplines, authors and works, the presence of regional books and the publishers.
\end{abstract}

KEYWORDS: History of Education. Didatic books. South of Mato Grosso.

\section{Resumen}

Se pretende presentar los procedimientos metodológicos para la creación de un catálogo analítico de manuales escolares que circularon en Mato Grosso (del Sur) en el siglo XX, así como el análisis de los resultados de esa búsqueda que localizó 266 manuales escolares. El análisis considera el período de publicación de las obras, la recurrencia de las disciplinas, autores y obras, la presencia de manuales regionales y las editoriales.

PALABRAS CLAVE: Historia de la Educación. Manuales Escolares. Sur de Mato Grosso.

\section{INTRODUÇÃO}

O presente artigo apresenta a finalização de uma investigação, coordenada por mim desde que iniciei a carreira como professora na Faculdade de Educação (FAED), da Universidade Federal da Grande Dourados (UFGD), em 2011, intitulada "Livros didáticos como fonte para a história da educação: catalogação e análise", e resulta de um catálogo analítico dos livros didáticos que circularam no estado de Mato Grosso (do Sul) ${ }^{1}$, durante o século XX.

\footnotetext{
* Doutora em Educação. Professora da Universidade Federal da Grande Dourados na Faculdade de Educação e no Programa de Pós-Graduação em Educação. Rua João Rosa Gois, 1761, Vila Progresso. Dourados. Fone (67) 3410-2121. E-mail: keniamoreira@ufgd.edu.br

${ }^{1}$ A pesquisa considera o estado de Mato Grosso uno, levando em conta que a criação do estado de Mato Grosso do Sul, com a divisão, só aconteceu em 1977. No entanto, a ênfase da pesquisa, pela sua filiação geográfica, é no
} 
Como parte desse projeto foram desenvolvidos planos de iniciação científica e monografias de final de curso de graduação, gerando mapeamentos das produções sobre o livro didático e entrevistas com ex-alunos e ex-professores. Ainda dentro desse projeto realizei meu pós-doutorado no Programa de Pós-Graduação em Educação, na Universidade Federal de Mato Grosso ${ }^{2}$, pesquisando a presença do livro didático, para o ensino secundário, em Mato Grosso, na Era Vargas. Tais movimentos investigativos, propiciaram a criação do catálogo que apresento neste artigo.

$\mathrm{O}$ interesse pelo livro didático como fonte/objeto de pesquisa iniciou-se no mestrado e continuou no doutorado, período em que a ênfase eram os livros didáticos da disciplina História, pela minha formação na área. Como professora na FAED/UFGD, na cadeira de História da Educação, o livro didático passou a ser encarado como uma potencial fonte para as investigações, tendo como respaldo teórico, em especial as pesquisas de Kazumi Munakata, Circe Bittencourt, Décio Gatti Junior, em âmbito nacional, do francês Alain Choppin, considerado o precursor das pesquisas com livros didáticos e dos espanhóis Agustín Escolano e Gabriela Ossenbach, com quem tive contato durante os estágios de doutorado e pós-doutorado. (As publicações desse período estão no Apêndice A).

O livro didático se converteu em uma das fontes privilegiadas para historiadores da educação em suas diferentes especialidades, dentre as quais a História do Currículo, a História das Disciplinas Escolares e a História das Instituições Escolares. Esse fato se deve, segundo Choppin (2017), às pesquisas acadêmicas que integram os avanços da história do livro desde 1980, além de se relacionar ao aumento da capacidade de armazenamento e aos progressos das técnicas de tratamento da informação. Com a renovação no âmbito da História da Educação, das linhas de investigação empreendidas e dos enfoques e métodos utilizados para desenvolvê-las, concentrando-se, a partir de então na denominada "história interna da escola", o livro didático passou a ser "um lugar de encontro obrigatório de diversos ramos da história da educação" e "convergem nele a história do currículo, a história das disciplinas escolares e a moderna história interna da escola ou da prática escolar, " como afirma Puelles Benítez (2000, p. 5).

De acordo com Tiana Ferrer (2017), o "olhar histórico" que examina o interior das instituições educativas, em busca do significado das atividades que nelas têm lugar, encontra na história do currículo um campo de estudos privilegiado. Especialmente a partir das décadas de 1960 e 1970, com a "Teoria Crítica do Currículo" e a "Nova Sociologia da Educação", constatou-se o caráter não meramente técnico e administrativo do currículo escolar. Nessa perspectiva, o conteúdo disciplinar do livro didático representa um dos aspectos do currículo, que, por sua vez, é compreendido, conforme Gimeno Sacristán (1995, p. 86-87), como a cultura real que surge de uma série de processos, mais que como um objeto delimitado e estático que se pode planejar e depois implantar; aquilo que é, na realidade, a cultura nas salas de aula, fica configurado em uma série de processos; as decisões prévias acerca do que se vai fazer no ensino, as tarefas acadêmicas reais que são desenvolvidas, a forma como a vida interna das salas de aula e os conteúdos de ensino se vinculam com o mundo exterior, as relações grupais, o uso e o aproveitamento de materiais, as práticas de avaliação, etc.

De acordo com essa perspectiva, o currículo não se resume a um campo em que simplesmente se busca a forma pedagogicamente mais adequada de selecionar, organizar, administrar e ministrar os conteúdos dos conhecimentos, mas "um conjunto de prescrições e práticas que, sob esse pretexto pedagógico, contribui para a reprodução das relações sociais

sul do Estado, abarcando o que hoje é delimitado como Mato Grosso do Sul, mas não o era durante todo o século $\mathrm{XX}$.

${ }^{2}$ O pós-doutoramento aconteceu entre junho de 2014 e junho de 2015, com bolsa PNPD, supervisionado pela professora doutora Elizabeth Figueiredo de Sá. 
existentes" (MUNAKATA, 2011, p. 1). Assim, uma das fontes históricas mais importantes para se abordar a história do currículo são os livros didáticos, que têm ocupado, desde a origem dos sistemas nacionais de educação, e ainda antes, um lugar destacado nas escolas de todos os países.

Do mesmo modo, os livros didáticos também se converteram em fonte privilegiada para a História das Disciplinas Escolares. Analisada como parte integrante da cultura escolar, conforme Chervel (1990) e Julia (2001), a história das disciplinas escolares é problematizada com base na gênese da disciplina, seus objetivos e seu funcionamento, ou seja, os objetivos e os conteúdos explícitos e os conteúdos pedagógicos, que por sua vez, correspondem aos exercícios e atividades necessárias às aprendizagens escolares. De acordo com Bittencourt (2003), entre as fontes utilizadas para investigar a história das disciplinas escolares, destacamse os livros didáticos, os programas curriculares e obras das ciências de referência. Em síntese, os livros didáticos aparecem como uma "magnífica fonte de informação (VALLS MONTÉS, 1999, p. 173).

Em 1980, o historiador inglês Harder (apud DELGADO, 2017, p. 16) pontuou algumas razões que justificariam o olhar atento do investigador sobre o livro didático enquanto fonte de pesquisa. Para ele, esse material é um meio para se conhecer as opiniões e ideias dos autores, professores e alunos; e nos auxilia a

\begin{abstract}
conhecer os mecanismos de comunicação das ideias em sociedade e a resistência que elas encontram em determinados grupos sociais, assim como o desgaste dessas ideias em determinados períodos. A análise do livro didático permite-nos, assim, observar as simplificações e distorções a que são submetidas as ideias ao serem transmitidas e o tempo transcorrido entre o lançamento de uma opinião e sua recepção e mudança na estrutura social.
\end{abstract}

Os livros didáticos indicam a distância em anos entre o conteúdo científico e as explicações em sala de aula, a quantidade de "ciência" introduzida pelo autor para o consumo escolar e a de "pedagogia e habilidade didática" que possui, igualmente o nível de conhecimento científico exigido do próprio professor. Indica ainda, como é levada em prática a política educativa de um país. Nesse caso, o historiador precisa considerar que não basta promulgar uma lei para que automaticamente se produza o exato cumprimento dos dispositivos legais. Além desses aspectos, Delgado (2017) acrescenta a importância das orientações metodológicas contidas nos livros didáticos, alocadas geralmente nos prólogos, notas de rodapé e "livro do professor". Nesses espaços, autores e editores indicam as atividades e exercícios a serem realizados sob a orientação do professor; também nesses espaços se encontram as concepções pedagógicas e os referenciais teórico-metodológicos. Sem desconsiderar, ainda, a interferência do próprio usuário, por meio de notas nas margens do livro, versos e exclamações, orações, desenhos, caricaturas, injúrias, anagramas, dentre outros, deixados por seus usuários, conforme Delgado (2017) e Bittencourt (1993).

O aspecto econômico é outro fator a ser considerado, como evidencia Munakata (2012). O preço de um livro pode ser a causa de sua rápida ou lenta difusão. Porém, nem sempre o número de exemplares vendidos avalia sua qualidade e aceitação, sobretudo, quando se trata de uma instituição, seja religiosa ou do Governo, que o impõe como obrigatório, diria Ossenbach (2007). Em síntese, além do valor pedagógico do livro didático, existem outros fatores nada descartáveis para a história da educação, como os fatores políticos, econômicos e sociológicos em geral.

Hernández Díaz (2008) afirma que, independente de ser ou ter sido muito questionada, a presença do livro didático nos centros escolares de todo o mundo é um fato indiscutível, pelo menos no contexto ocidental. Enquanto fonte, têm despertado crescente interesse pelo 
estudo da cultura material da escola, pelos elementos visíveis, tangíveis, que intervêm na vida interna escolar, gerando um visível esforço organizativo e hermenêutico entre os historiadores da educação, produzindo bens e reflexões significativos.

Para Corrêa (2000), a contribuição do livro didático como fonte para a história das instituições escolares está na possibilidade de entender a instituição escolar por dentro, já que esse tipo de material é portador de parte dos conteúdos do currículo escolar naquilo que diz respeito ao conhecimento. Aliás, dependendo do período histórico no qual for tomado como fonte, esse tipo de material pode ser considerado como o portador supremo do currículo escolar no que tange aos conhecimentos que eram transmitidos nas diferentes áreas, quando se constituiu em única referência, tanto para professores quanto para alunos (CORRÊA, 2000, p. 13). Para a autora, o livro didático contribui para avançar na direção da pesquisa sobre a instituição escolar também no que diz respeito à circulação e ao uso dos materiais de ensino em seu interior e estabelecer relações entre este e as compreensões epistemológicas sobre a educação, a aprendizagem escolar, a didática e a metodologia de ensino, no sentido de entendê-las através das práticas escolares, meios de seus desdobramentos concretos nesta instituição (CORRÊA, 2000, p. 13- 14).

Justificada a importância de estudos investigativos sobre livros didáticos, a importância de sua catalogação se justifica como forma de facilitar a localização, acesso e seleção deste objeto para diferentes análises que possa possibilitar. No Brasil e no mundo, de modo geral, ainda são poucos os esforços no sentido de catalogar o livro didático como fonte de investigação. Ao nível internacional, destacamos o Instituto Georg Eckert, na Alemanha ${ }^{3}$, o projeto EMMANUELLE, na França ${ }^{4}$, e o projeto MANES, na Espanha ${ }^{5}$. No caso brasileiro, destacamos o projeto LIVRES, com seu Banco de Dados de Livros Escolares Brasileiros (Livres), vinculado à Faculdade de Educação, da Universidade de São Paulo (FEUSP) ${ }^{6}$.

Para apresentar um catálogo de livros didáticos que circularam em Mato Grosso (do Sul) no século XX, que montei a partir da investigação aqui apresentada, divido o texto em duas partes: 1 Procedimentos metodológicos: criação do catálogo; 2 Resultado: O Catálogo.

\section{Procedimentos metodológicos para a criação do catálogo}

Aqui apresento dois principais procedimentos utilizados para a localização e seleção dos livros didáticos utilizados em Mato Grosso (do Sul) no século XX. O primeiro pelo conjunto de esforços realizados durante o pós-doutoramento, que se restringe aos livros que

\footnotetext{
3 O Instituto Georg Eckert para a Investigação Internacional sobre Livros Didáticos, com sede em Braunschweing (Alemanha), criado nos anos 1970, apesar de não se dedicar ao trabalho histórico sobre os livros escolares, tem realizado importantes contribuições neste âmbito, abrigando uma biblioteca de livros didáticos e várias publicações sobre o tema.

${ }^{4} \mathrm{O}$ projeto EMMANUELLE, desenvolvido pelo Institut National de Recherche Pédagogique (INRP), foi criado na França em 1980. Dirigido por Alain Choppin, o projeto EMMANUELLE, inserido no Service d'Histoire de l'Education do INRP, apresentou uma dupla tarefa: documental e investigadora. A base de dados do projeto EMMANUELLE, que objetivava registrar todos os livros escolares publicados na França desde a Revolução até os dias atuais, se construiu sobre o programa CDS-ISIS, elaborado pela UNESCO

${ }^{5} \mathrm{O}$ projeto MANES iniciou-se em 1992, fazendo parceria com o projeto EMMANUELLE e com o objetivo fundamental de realizar o estudo histórico dos livros didáticos publicados na Espanha entre 1808 e 1990.

${ }^{6} \mathrm{O}$ acervo do Livres disponibiliza, por meio de seu Banco de Dados pela Internet, o acesso aos títulos das obras didáticas de diversas disciplinas escolares brasileiras de 1810 a 2005. O acesso ao Banco de Dados LIVRES se restringe aos dados bibliográficos e formatação. A consulta detalhada de obra e conteúdo deve ser feita presencialmente na própria biblioteca da FEUSP, com agendamento.
} 
circularam em Mato Grosso (uno) durante o primeiro governo da era Vargas (1930-1945). O segundo pelo mapeamento da produção acadêmica no e sobre Mato Grosso (uno) que tiveram como fonte/objeto o livro didático. No entanto, a criação do catálogo foi possível, principalmente, pela doação de livros didáticos, de diversas partes, recebidos durante o período de execução do projeto.

\section{Procedimentos de localização durante o pós-doutoramento}

Meu objetivo principal era a criação de um catálogo dos livros didáticos para o ensino secundário, utilizados na Era Vargas em Mato Grosso (uno), facilitando, desse modo, futuras pesquisas sobre o tema, contribuindo para ampliar este campo de investigação, já iniciado por outros pesquisadores brasileiros, bem como, por pesquisadores de outros países ${ }^{7}$. Para tanto, a primeira iniciativa foi buscar as fontes que indicassem tais livros didáticos. As buscas foram feitas nos seguintes arquivos:

- Acervo Digital do Grupo de Pesquisas História da Educação e Memória-UFMT (GEM) ${ }^{8}$. No Acervo do GEM-UFMT, foi possível encontrar os seguintes documentos que contemplam o período de análise: Relatórios da Instrução Pública (1930, 1931, 1939, 1943 e 1944);

Regulamento da Instrução Pública (1942); Correspondências da Secretaria de Instrução, que apesar de só listar a referência dos dados de catalogação dos documentos, apresenta o conteúdo de cada correspondência; Jornal A Cruz (1930,1938 e 1939); Mensagens dos governadores do Estado (1930 e 1937). Alguns poucos documentos fazem menção a livros didáticos, de modo geral, mas nenhuma obra é citada.

- Arquivo Público do Estado de Mato Grosso (APMT). Nas visitas realizadas a este Arquivo, atentei-me, especialmente em investigar a presença de propagandas de livros didáticos nos periódicos que circularam em Mato Grosso, tendo em vista que boa parte do acervo, referente à história da educação mato-grossense, no período de primeira e segunda República estão disponíveis no Acervo do GEM. Para tanto, analisei 19 periódicos diferentes, de números de edição variados. Nenhuma menção a livros didáticos foi encontrada.

No acervo do APMT localizei no Diário Oficial do Estado de Mato Grosso, datado de 8 de maio de 1940, a movimentação de consultas realizadas na Biblioteca e Arquivo Público do Estado, realizadas entre 16 a 31 de janeiro, com estatísticas de consultas por classe (área de conhecimento do livro) e por língua (idioma da obra). A publicação apresenta ainda uma lista dos autores mais consultados. E, o Diário Oficial do Estado de Mato Grosso, de 22 de janeiro de 1941, por sua vez, apresenta uma lista de materiais didáticos que inclui livros didáticos, mais especificamente, as seguintes cartilhas e livros de leitura: Cartilha das Mães; Cartilha da Infância; Cartilha na Roça; Cartilha Meu Livro; Livro de leitura "Sei ler" ( $1^{\circ}, 2^{\circ}$, e $3^{\circ}$ ano); Livro de leitura "Meus deveres" (col.); Livro de leitura "Minha Pátria" (col.); Livro de leitura "Meu livro"; e, Livro de leitura série "O Bom Colegial".

- Centro de Documentação Regional da Universidade Federal da Grande Dourados (CDR$U F G D$ ). Nos sete periódicos pedagógicos disponíveis no acervo, busquei propagandas, ou qualquer menção a de livros didáticos. Nenhuma menção a algum livro didático específico.

\footnotetext{
${ }^{7}$ Destacamos a obra organizada por Agustin Escolano: "Historia ilustrada del libro escolar en España", em três volumes.

${ }^{8}$ Disponível em www.gem.ufmt.br. Acesso em: 3 nov. 2014. No Acervo do GEM-UFMT, foi possível encontrar os seguintes documentos que contemplam o período de análise: Relatórios da Instrução Pública (1930, 1931, 1939, 1943 e 1944); Regulamento da Instrução Pública (1942); Correspondências da Secretaria de Instrução, que apesar de só listar a referência dos dados de catalogação dos documentos, apresenta o conteúdo de cada correspondência; Jornal A Cruz (1930,1938 e 1939); Mensagens dos governadores do Estado (1930 e 1937).
} 
- Acervo da Casa Barão de Melgaço (CBM), disponível on-line 9 , que inclui o Arquivo do Instituto Histórico de Mato Grosso (IHMT). Destaco deste acervo a coleção "Bibliografia Mato-grossense. Relação dos trabalhos publicados em Mato Grosso ou que interessam ao mesmo estado, existentes na Biblioteca da Casa Barão de Melgaço", organizado por José de Mesquita e Firmo Rodrigues, publicado em 1944. As obras listadas datam da segunda metade do século XIX até o ano de 1943. Estão separadas por categorias: "Literatura-Poesia", "Literatura-Prosa", "História", "Geografia e Etnografia", "Teses e Memórias", "Religião", "Direito", "Política", "Relatórios", "Relatórios Municipais", "Relatórios Diversos", "Leis Provinciais", "Leis Estaduais", "Comissão Rondon", "Estatutos, Prospectos e Catálogos", "Arte Militar" e "Revistas". A relação da coleção tem 37 páginas. Nenhum livro, intitulado ou reconhecido como didático, consta na lista da coleção da biblioteca Mato-grossense.

- Arquivo do Liceu Cuiabano (ALC). Entre os documentos relacionados, selecionei: Pontos e teses para provas parciais de diferentes disciplinas e séries, entre 1941 e 1942; "Resumo da matéria dada durante o mês", de diferentes disciplinas e séries, entre 1940 e 1942, horários de aulas e mapas de aulas dadas de diferentes disciplinas e séries, além de uma lista de "Aquisição de material didático" para as aulas de Educação Física, para o Laboratório de História Natural, e para a sala de Desenho. No entanto, nenhum desses documentos faz menção a livros didáticos.

- Arquivo do Centro de Pesquisa e Documentação de História Contemporânea do Brasil $(C P D O C)$. Em visita ao acervo do CPDOC, na cidade do Rio de Janeiro, selecionei para análise, os seguintes documentos: O manifesto "O livro e o papel", edição do centro dos fabricantes nacionais de papel (1934); a obra "O problema do livro no Brasil" de Galvino Filho (1938); e, o Catálogo "Exposição do Livro Brasileiro em Motevideu" (1939). Os três documentos levaram a questionar se é possível falar em produção de livros em Mato Grosso na Era Vargas, dadas as dificuldades de produção em nível nacional, como a falta de mercado, o preço do livro, a dificuldade de distribuição para outros estados fora do eixo Rio-São Paulo e o índice de analfabetismo, dentre outros fatores, no referido período.

O Catálogo "Exposição do Livro Brasileiro em Motevideu" é uma publicação do Ministério da Educação e Saúde, datado de 1939, impresso pelo Serviço Gráfico do Ministério da Educação, Rio de Janeiro. A seção "Livro Didáticos" apresenta 79 obras para o ensino primário, 144 para o ensino secundário, 27 para o ensino profissional e quatro obras para música, totalizando 254 livros didáticos em circulação no ano de 1939. O Catálogo, por não apresentar ano das obras, nem número de edição, não nos permite analisar o período de produção dos livros citados. Porém, pelas obras listadas no Catálogo, não é possível encontrar nenhum vestígio de livros didáticos que foram usados nas escolas mato-grossenses.

- Jusbrasil com publicações no Diário Oficial da União (DOU), disponível no site Jusbrasil 10. Encontrei a publicação de 4 de abril de 1940 com a relação geral dos livros didáticos aprovados pela Comissão Nacional de Livros Didáticos (CNLD) até a presente data. 635 obras foram julgadas, conforme indica o documento, tendo sido aprovadas 455 sem restrições e 56 com restrições. 122 obras foram impugnadas. No entanto, não apresenta qualquer vestígio de circulação e usos no contexto escolar mato-grossense.

\section{Mapeamento da produção acadêmica}

\footnotetext{
${ }^{9}$ Disponível em: http://www.casabarao.com.br . Acesso em: 10 dez. 2014.

10 Disponível em: http://www.jusbrasil.com.br/diarios/2196428/pg-11-secao-2-diario-oficial-da-uniao-dou-de04-04-1940. Acesso em: 07 jan. 2015.
} 
Para mapear a produção acadêmica em história da educação no estado de Mato Grosso e Mato Grosso do Sul, que utilizou o livro didático como fonte/objeto de investigação, considerei como locais de busca os sites de banco de dados, de periódicos e eventos da área. Foram considerados: o Banco de Teses e Dissertações da CAPES e a Biblioteca Digital de Teses e Dissertações. Como periódicos: a Revista Brasileira de História da Educação (RBHE); a Revista Cadernos de História da Educação (RCHE), a Revista História da Educação (RHE-UFRGS) e a Revista do HISTEDBR. Entre os anais de eventos da área: o Congresso Iberoamericano de História da Educação Latino-Americano (CIHELA), o Congresso Luso-Brasileiro de História da Educação (COLUBHE), o Congresso Brasileiro de História da Educação (CBHE), a Reunião Anual da Associação Nacional de Pós-Graduação e Pesquisa em Educação no Centro Oeste (ANPEd Centro Oeste), o Encontro de História de Mato Grosso do Sul, organizado pela seção de Mato Grosso do Sul da Associação Nacional de História (ANPUH-MS), e o Encontro de História da Educação do Centro Oeste (EHECO).

Como descritores de busca utilizei o termo "Mato Grosso" considerando a divisão do Estado em 1977, além das variações dos termos específicos para "livro didático", conforme Moreira (2017), que inclui os termos cartilha, livro-texto, manual escolar, etc. Considerei as produções no e sobre Mato Grosso, o que significa considerar: as universidades e programas aos quais os autores estão vinculados no momento de sua identificação na publicação, bem como as produções publicadas fora do Estado, mas que apresentavam no título o termo "Mato Grosso". Considerei as publicações que apresentaram no título e/ou resumo e/ou palavraschave os descritores "Livro didático" e suas variações e "Mato Grosso" e "Mato Grosso do Sul".

Localizei 15 dissertações e duas teses, nove artigos em periódicos e nove artigos em anais de eventos, totalizando 35 trabalhos. De forma sintética, podemos afirmar que as instituições com maior produção sobre o tema foram: a Universidade Federal de Mato Grosso, com 13 publicações. Das instituições de Mato Grosso do Sul, temos: a Universidade Federal da Grande Dourados, com sete trabalhos e recorrência da autora Kênia Hilda Moreira; a Universidade Estadual de Mato Grosso do Sul, com seis trabalhos e recorrência das autoras Carla Villamaina Centeno e Estela Natalina Mantovani Bertoletti; a Universidade Federal de Mato Grosso do Sul, com cinco trabalhos, sem recorrência de autoria, a UCDB e a Uniderp, com um trabalho cada uma. E uma ocorrência para a Unesp.

Nem todos os trabalhos apresentaram uma preocupação histórica e/ou delimitaram o recorte temporal da pesquisa, mas dentre os que delimitaram, percebe-se que o período histórico mais investigado, com a mesma proporção de recorrência, são: a primeira República (1889-1930) e a Era Vargas (1930-1945). Em seguida, com igual proporção, o período imperial (século XIX) e o período da ditadura militar (em especial as décadas de 1970 e 1980). Os trabalhos que não apresentaram delimitação temporal ou se atentaram ao período atual da investigação, foram a maioria, o que retrata a escassez de pesquisas em história da educação no Estado tendo o livro didático como fonte/objeto.

Sobre o período de produção/publicação das investigações localizadas, a mais antiga data de 2008 e a mais recente de 2016 (ano da nossa última busca). Em primeiro lugar aparece o ano de 2014 (8 produtos), talvez em virtude de algum evento, em seguida o ano de 2011 (7 produtos), 2013 (6 produtos), 2010 e 2012 (4 em cada ano). Apenas uma ocorrência para 2008 e duas para 2016, o que evidencia que o período áureo está entre essa delimitação inicial e final, e não nos extremos.

Nem todos os trabalhos tiveram como foco uma disciplina escolar específica, mas entre os que escolheram uma matéria de ensino temos, em primeiro lugar a disciplina de História (muitas vezes História do Brasil), com 12 ocorrências, seguida da disciplina de 
português, com sete ocorrências, matemática com quatro. Além dessas disciplinas também estiveram presentes, a alfabetização (cartilha), a biologia (ciências), sociologia, literatura e inglês. As temáticas eleitas pelos autores foram muito variadas, não nos permitindo um quadro estatístico de abordagens. No entanto, pode-se afirmar que grande parte das investigações se ativeram em fazer análise de conteúdo dos livros didáticos.

A escassez de autores de referência permitiu inferir a ausência de grupos específicos sobre o livro didático como fonte para a história da educação em Mato Grosso do Sul, uma vez que grande parte dos autores se atêm ocasionalmente a escrever um texto tendo o livro didático como fonte/objeto, mas seu tema de pesquisa principal passa por outros objetos e/ou interesses. Tal constatação me faz rememorar a afirmação de Choppin (2004, p. 557-558) para quem o livro didático tornou-se "um tema relativamente simples para o pesquisador iniciante" ou, atraente de maneira ocasional, para o pesquisador da educação, como complemento. No entanto, a recorrência dos autores Bertoletti, Centeno e Moreira evidenciam um relativo esforço de pesquisas sobre o tema.

Desse mapeamento da produção foram localizados 98 livros didáticos, que serão analisados a seguir.

\section{Resultado: O Catálogo}

A primeira versão do catálogo analítico dos livros didáticos utilizados em Mato Grosso (do Sul) no século XX é composta, portanto, de 98 títulos didáticos listados a partir das pesquisas que compõem o mapeamento da produção apresentado acima, nenhuma obra resultante dos procedimentos metodológicos de busca durante o pós-doutoramento, e 168 livros didáticos oriundos de doações diversas, durante a execução do projeto, totalizando 266 livros didáticos, com vestígios de circulação no tempo/espaço delimitado.

As obras doadas encontram-se fisicamente disponíveis no LADHEME (Laboratório de Documentação, História da Educação e Memória). No entanto, não disponho da materialidade dos livros didáticos localizados via mapeamento da produção, o que também significa dizer que, muitas vezes, não tive acesso a todos os dados catalográficos dessas obras, ficando na dependência das informações apresentadas por cada pesquisador.

Apresento abaixo o quadro modelo, utilizado para catalogar cada obra individualmente, contendo informações sobre a identificação e a materialidade de cada livro. O quadro de catalogação teve como modelo o catálogo do Banco de Dados LIVRES (Biblioteca da USP).

Quadro 1 - Modelo preenchido de quadro de catalogação de livro didático

\begin{tabular}{|c|c|c|}
\hline Título: & Ciência e Sociedade & \\
\hline Autor(es): & $\begin{array}{l}\text { Bertoldi, Odete Gasparello; } \\
\text { Rauter de }\end{array}$ & Vasconcelos, Jacqueline \\
\hline Editora: & Scipione & \\
\hline Local: & São Paulo & \\
\hline Impressor: & & \\
\hline Ano Publicação: & 2000 & \\
\hline
\end{tabular}




\begin{tabular}{|ll|}
\hline Nível: & $6^{\text {a }}$ série do ensino fundamental \\
Idioma: & Português \\
Gênero: & Manual \\
Descrição: & $27,5 \times 20 \mathrm{~cm} / 318 \mathrm{p}+100$ p de manual pedagógico \\
Notas: & $\begin{array}{l}\text { De acordo com os PCNs. Livro do professor venda } \\
\text { proibida. }\end{array}$ \\
Disciplina: & Ciências \\
Classificação: & \\
Ilustrações: & Sim \\
Exemplares: & 1 \\
Observações: & \\
\hline
\end{tabular}

Fonte: Catálogo de Livros Didáticos em Mato Grosso (do Sul) no século XX.

Os procedimentos que resultaram na localização das 266 obras didáticas, seja pelas pesquisas mapeadas, seja pelas doações, permite afirmar que há indícios, conforme Ginzburg (1987), de que tais obras foram utilizadas durante o século XX em Mato Grosso (do Sul), considerando que: o recorte geográfico das pesquisas delimita-se nos espaços de Mato Grosso/Sul de Mato Grosso/Mato Grosso do Sul e que as doações foram feitas por moradores da região. No entanto, o número de obras localizadas, considerando o mesmo procedimento, não é digno de maiores análises, ciente da falta de rigor que tal número evidencia. Ainda assim, apresento a seguir, breves dados quantitativos das obras didáticas, separadas, a princípio, por procedimento de localização: primeiro as obras que compõem as pesquisas; e em seguida as obras doadas. Compõe as questões de análise do catálogo: o ano de publicação dos livros didáticos; as disciplinas mais recorrentes; a existência de obras regionais, a recorrência de autores e obras, dentre outras.

Entre as 98 obras didáticas selecionadas a partir das pesquisas localizadas, nem todas apresentam dados exatos sobre os livros didáticos analisados, mas as informações disponíveis permitem afirmar que oito livros pertencem a primeira década do século XXI, estando, portanto, fora do nosso recorte temporal, passando a 91 obras. Cabe destacar que, apesar de buscar as pesquisas especialmente em meios de divulgação da área da história da educação, um número significativo de produções localizadas atém-se ao tempo presente.

No entanto, um terço dos livros didáticos identificados nas pesquisas foram produzidas e/ou circularam na primeira metade do século XX (31 livros didáticos). Em número menor, a década de 1970 (16 livros), seguida pela década de 1990 (11 livros); e a década de 1980 (10 livros). Sobre os títulos didáticos da primeira metade do século, enfatizo a importância de os investigadores detalharem sobre seus procedimentos de localização, identificação e seleção das fontes, para facilitar a pesquisa de investigações posteriores, pois como lembra Collados Cardona (2008, p. 325), o trabalho com os livros didáticos considerados geralmente como objetos de consumo - "frequentemente dispersos, e fisicamente muito vulneráveis, faz com que a simples localização e catalogação de exemplares consumam considerável energia nos trabalhos de campo".

No que diz respeito a disciplina escolar presente nos livros didáticos analisados pelas pesquisas, considerando as obras que circularam no século $\mathrm{XX}$, apresento a seguinte ordem decrescente: História (34); Português/literatura (28); Sociologia (7); Matemática (6); Cartilhas/alfabetização (5); Ciências/Biologia (3); Geografia/corografia (3). Além desses, uma 
ocorrência para os seguintes manuais didáticos destinados à formação de professores: "Noções de Higiene"; "Didactica (Nas escolas Primárias)"; "Pedagogia Científica: Psicologia e direção da aprendizagem"; e "Noções de Psicologia Aplicada à Educação".

Entre os livros de História e Geografia, identifico as seguintes obras regionais: "História de Mato Grosso: da ancestralidade aos dias atuais"; "O processo histórico de Mato Grosso"; "Revivendo Mato Grosso"; "História de Mato Grosso do Sul" de Lori Gressler; "Quadro Corográfico de Mato Grosso" (1906); e "Álbum Gráfico de Mato Grosso" (1914).

Cabe lembrar que o número de livros por disciplina, bem como a recorrência de obras em uma década, não significa necessariamente que mais pesquisas foram feitas sobre tal matéria ou tal período, porque enquanto um pesquisador delimita um número restrito de livros didáticos como fonte, outros alargam esse número, como por exemplo, uma dissertação que usou mais de 20 livros didáticos de língua portuguesa que circularam durante a ditadura militar no Brasil. Por fim, entre os livros didáticos identificados como fonte das pesquisas, não localizamos significativa recorrência de obras ou autores didáticos.

No que diz respeito ao ano de publicação das obras didáticas doadas, 22 pertencem ao século XXI, que excluídas do total de 168 livros doados, resultam em 146. Desse total, lembrando que nem todas as obras apresentam ano de publicação, têm-se a seguinte ordem decrescente: em primeiro lugar a década de 1990 (67 obras); a década de 1980 (41 obras); a década de 1970 (11 obras) e uma ocorrência para a ano de 1950 (um livro didático de inglês).

No entanto, comporão o catálogo uma coleção de obras raras, de livros didáticos de História do Brasil do século XIX e primeira metade do século XX, bem como a última doação, recebida de uma professora aposentada - do seu tempo de aluna e do tempo de professora - que por terem chegado recentemente, ainda não foram catalogados. Isso significa que, apesar da predominância dos livros didáticos doados na década de 1990, o que resulta em um período bastante recente, o catálogo contará com obras raras do século XIX, bem como algumas obras da primeira metade do século XX, de História e de Francês, por exemplo.

No quesito disciplinas escolares, as obras doadas e catalogadas até o momento estão assim divididas: Ciências: 53 (com títulos didáticos variados, tais como: "Ciências Matéria, Formas de Energia, Iniciação à Mecânica"; "Ciências O Ecossistema Fatores Químicos e Físicos"; "Ciências Entendendo a Natureza", e "Os seres vivos no ambiente"). Somadas a Biologia: 9; Físicalquímica: 2, teríamos 64 obras. A primeira ocorrência para tal área data de 1979.

História (Geral e do Brasil): 21. Há, entre esse montante, livros didáticos de história da França, em francês, paraguaios e uruguaios, em espanhol. A primeira ocorrência data de 1974.

Português/literatura: 17 (alguns livros apresentam a teoria literária, a língua portuguesa e a produção de textos em um mesmo título, como a obra: "Língua, Literatura e Produção de Textos"). A primeira ocorrência dessa área data de 1976.

Matemática: 14. A primeira ocorrência é de 1976. Com menor proporção as disciplinas de: Religião (8); Geografia (6); Inglês (3); Espanhol (1); Estudos Sociais (1); Desenho geométrico (1); e Educação, Moral e cívica (1).

Entre os livros técnicos, uma ocorrência para cada uma das seguintes obras: Teórica geral da administração; Citologia, Histologia e embriologia; Mecânica vetorial para engenheiros (dinâmica); Mecânica vetorial para engenheiros (estática); Qualificação profissional para o magistério (n. 1, 2, 3, 5, 6).

Igualmente não houve recorrência de obras ou autores que merecessem destaque.

O catálogo das obras doadas também permitiu levantar as editoras recorrentes, entre os livros didáticos, com a seguinte ordem decrescente: Ática (27); FTD (20); Moderna (18); Saraiva (15); Scipione (13); Ibep (6); Editora Atual (6); FUNTEVÊ (5); Editora Lê (3); McGraw-Hill (3); Ediouro (2); e Editora Eduarte (2). Tal levantamento permite evidenciar as 
editoras em destaque no mercado de livros didáticos no período, e a concentração dessas empresas no estado de São Paulo, com pouco espaço para variação. Entre as editoras com apenas uma ocorrência estão: Brasiliense; Companhia editora nacional; Editora do Brasil; Editora Formato; Editora Globo S. A.; Editora Itatiaia; Editora Nova Geração; GEMSA (Edições Michalany); Pueri Dons; e Quinteto Editorial.

\section{REFERÊNCIAS}

BITTENCOURT, Circe M. F. Disciplinas escolares: História e pesquisa. In: OLIVEIRA, et al. (Orgs.) História das disciplinas escolares no Brasil: contribuições para o debate. Bragança Paulista: EDUSF, 2003.

BITTENCOURT, Circe M. F. Livro didático e conhecimento histórico: uma história do saber escolar. São Paulo, 1993. Tese (Doutorado em História Social) - Universidade de São Paulo, São Paulo, 1993.

CHERVEL, A. História das Disciplinas Escolares: reflexões sobre um campo de pesquisa. Teoria \& Educação, Porto Alegre, n. 2, p. 177-229, 1990.

CHOPPIN, A. Os livros didáticos de ontem a hoje: o exemplo da França. In. MOREIRA, K. H.; HERNANDÉZ DÍAZ, J. M. (Org.). História da educação e livros didáticos. CampinasSP: Pontes Editores, 2017, p. 81-124.

COLLADOS CARDONA, E. El concepto de dibujo y su práctica en los libros de texto de educación primaria publicados en España en el periodo comprendido entre 1915-1990. Historia de la Educación, Revista Interuniversitaria, Salamanca, n. 27, 2008, pp. 323-346.

CORRÊA, R. L. T. O livro escolar como fonte de pesquisa em História da Educação. Caderno CEDES, Campinas, n. 52, v. 20, nov. 2000, pp. 11-24.

DELGADO, Buenaventura. Os livros didáticos como fonte para a história da educação. In. MOREIRA, K. H.; HERNANDÉZ DÍAZ, J. M. (Org.). História da educação e livros didáticos. Campinas-SP: Pontes Editores, 2017, p. 15-22.

GINZBURG, C. Sinais: Raízes de um paradigma indiciário. In: GINZBURG. C. Mitos, emblemas, sinais: morfologia e história. São Paulo: Companhia das Letras, 1987.

HERNÁNDEZ DÍAZ, J. M. H. (Org.) Libros escolares para la educación de las niñas en España (1838-1970). Salamanca: Universidad de Salamanca, 2008. 
JULIA, D. A cultura escolar como objeto histórico. Revista Brasileira de História da Educação. Campinas, SP: SBHE/Ed. Autores Associados, 1o número, 2001.

MUNAKATA, Kazumi. História das disciplinas escolares e do livro didático. Disponível em: http://www.pucsp.br/pos/ehps/1/links_pesquisas/historia_disciplinas_escolares.php . Acesso em: 20 mar. 2011.

MUNAKATA, Kazumi. O livro didático como mercadoria. Pro-Posições. V. 23, n. 3 (69), p. 51-66, set./dez. 2012.

OSSENBACH SAUTER, Gabriela. Simpósio Internacional de Livro Didático. FEUSP, 0611-2007 (palestra).

PUELLES BENÍTEZ, M. de P. Los manuales escolares: un nuevo campo de conocimiento. Revista Interuniversitaria - Historia de la Educación. Salamanca, n. 19, 2000, p. 5-10.

GIMENO SACRISTÁN, José. Currículo e diversidade cultural. In: Territórios contestados: O currículo e os novos mapas políticos e culturais. Tomaz Tadeu da Silva e Antônio Flávio Barbosa Moreira (orgs.). Petrópolis, RJ: Vozes, 1995.

TIANA FERRER, A. O projeto Manes e a investigação histórica sobre os livros didáticos (séculos XIX e XX). In. MOREIRA, K. H.; HERNANDÉZ DÍAZ, J. M. (Org.). História da educação e livros didáticos. Campinas-SP: Pontes Editores, 2017, p. 23-48.

VALLS MONTÉS, R. V. De los manuales de Historia a la historia de la disciplina escolar. Historia de la Educación, Revista Interuniversitaria, Salamanca, n. 18, p. 169-190, 1999.

\section{APÊNDICE A - Produções sobre livro didático}

Tese:

MOREIRA, K. H. O ensino de história do Brasil no contexto republicano de 1889 a 1950 pelos livros didáticos: análise historiográfica e didático-pedagógica. 2011. 236 f. Tese (Doutorado em Educação Escolar) - Unesp, Araraquara-São Paulo, 2011.

\section{Dissertação:}

MOREIRA, K. H. O Livro Didático de História: mapeamento das pesquisas acadêmicas 
(teses e dissertações) realizadas entre 1980 a meados de 2005. 2006. 171 f. Dissertação (Mestrado em Educação Escolar) - Unesp, Araraquara-São Paulo, 2006.

\section{Artigos:}

MOREIRA, Kênia Hilda. Pesquisas em História da Educação com o livro didático: questões sobre fontes, temas e métodos. Revista de Educação Pública. v. 26, p. 877 - 903, 2017.

Livros didáticos de História do Brasil para o ensino secundário (1889-1950): procedimentos de localização, seleção e acesso. Revista Educação e Fronteiras On-line. V. 7, n. 20, p. 68-91, 2017.

SILVA, Luciana V. C. A.; MOREIRA, Kênia Hilda. O livro didático 'Estudo Dirigido de Português' nos anos 1970. Revista Eletrônica Documento/Monumento. v. 20, p.129 - 140, 2016.

MOREIRA, Kênia Hilda. Os livros didáticos de História do Brasil para o Ensino Secundário na Era Vargas: entre autores, didáticas e programas curriculares. Cadernos de História da Educação (Online), v.15, p.723 - 742, 2016.

SA, Elizabeth. Figueiredo.; MOREIRA, Kênia Hilda. Desafios da pesquisa com livros didáticos em Mato Grosso (1930-1945). Revista Eletrônica Documento/Monumento, v.15, p.257 - 276, 2015.

MOREIRA, Kênia Hilda; PASSONE, Eglem de Oliveira; NEVES, Samara. G. O livro didático como fonte de pesquisas em história da educação no centro oeste: entre temas, períodos e métodos. História e Diversidade, v.1, p.111 - 125, 2014.

O ensino de História do Brasil no contexto republicano (1889 a 1960): uma análise da historiografia didática. Revista Eletrônica Documento/Monumento. v. 9, n. 1, p.109-126, 2013.

MOREIRA, Kênia Hilda; PASSONE, Eglem de Oliveira. O Livro Didático e as Tecnologias de Informação e Comunicação na Educação Escolar: o livro didático sobreviverá às novas tecnologias? Revista: EaD \& Tecnologias Digitais na Educação. v.2, p.57-68, 2013.

MOREIRA, Kênia Hilda. Livros didáticos como fonte de pesquisa: um mapeamento da produção acadêmica em História da educação. Revista Educação e Fronteiras On-Line. v.2, p.129-142, 2012. 
Povo brasileiro nos livros didáticos de História republicanos: 1889-1950. História revista (UFG. Impresso), v.17, p.34 - 46, 2012.

MOREIRA, Kênia Hilda; Pinheiro, Alexandra. Livros de leitura na primeira metade do século XX: concepções de leitura e de leitores. Interletras (Dourados). v.12, p.1 - 18, 2010.

MOREIRA, Kênia Hilda. Livros didáticos de História no Brasil do século XIX: questões sobre autores e editores. Revista Educação e Fronteiras On-Line, v.3, p.31-44, 2010.

. Uma leitura discursiva dos livros didáticos: considerações sobre escrita, leitor e autoria. Linguasagem (São Paulo). v.1, p.1 - 12, 2009.

\section{Dossiê}

MOREIRA, Kênia Hilda; MUNAKATA, Kazumi. Dossiê: Livros didáticos como fonte/objeto de pesquisa para a história da educação no Brasil e na Espanha. Revista Educação e Fronteiras On-line. V. 7, n. 20, p. 68-91, 2017.

\section{Livros:}

MOREIRA, Kênia Hilda; SILVA, Marilda da. Um inventário: livros didáticos de História em pesquisas. São Paulo: EdUnesp, 2011.

MOREIRA, Kênia Hilda; DIAZ, J. M. H. História da Educação e Livros Didáticos. Campinas: Pontes Editores, 2017, v.1. p.268.

\section{Capítulos de livros:}

MOREIRA, Kênia Hilda; PASSONE, Eglem de Oliveira. As pesquisas em história da educação no Brasil com o livro didático In: História da Educação e Livros Didáticos. Campinas: Pontes Editores, 2017, p. 49-80.

MOREIRA, Kênia Hilda. Livros didáticos como fonte para a História da Educação: possibilidades e desafios. In.: SANTOS, Reinaldo; FURTADO, Alessandra Cristina. História da Educação, Memória e Sociedade. Dourados, MS, Ed. UFGD, 2015, pp. 85-102.

Investigaciones sobre libros didácticos en universidades brasileñas: métodos, temas y líneas de investigaciones entre 1980 y 2010 In: Formación de élites y educación superior en iberoamerica (SS. XVI-XXI). Salamanca: Hergar Ediciones Antema, 2012, v. 2, p. 681-695. 
O povo nos livros didáticos de história (1889-1950) In: História da educação escolar: múltiplas fontes; múltiplos olhares. São Carlos-SP: Pedro e João Editora, 2012, p. 131-152.

Influência inglesa nos livros didáticos de história do Brasil no século XIX: a contribuição de History of Brazil, de Robert Southey In: Influencias Inglesas en la Educación Española e Iberoamericana (1810-2010). Salamanca: Hergar Ediciones Antema y Alex, 2011, v.1, p. 525-533.

Pesquisa em História da Educação: Localização e seleção de livros didáticos de História republicanos (1889 a 2008) In: História da Educação no Brasil: matrizes interpretartivas, abordagens e fontes predominantes na primeira década do século XXI. Vitória-ES: Editora UFES/SBHE, 2011, p. 215-240.

Convivência escolar e a questão indígena nos livros didáticos: para uma educação intercultural In: La Convivencia Escolar: Aspectos Psicologicos y educativos. AlmeriaEspanha: Editorial GEU, 2010, v.1, p. 451-457.

Pesquisas Acadêmicas sobre livro didático de História: um balanço quantitativo de 1980 a meados de 2005 In: Sala de aula: desafios e perspectivas para a produção do saber. Goiânia: Editora da UCG, 2006, p. 34-46.

Recebido em: 08 de março/2018

Aprovado em: 10 de julho/2018 